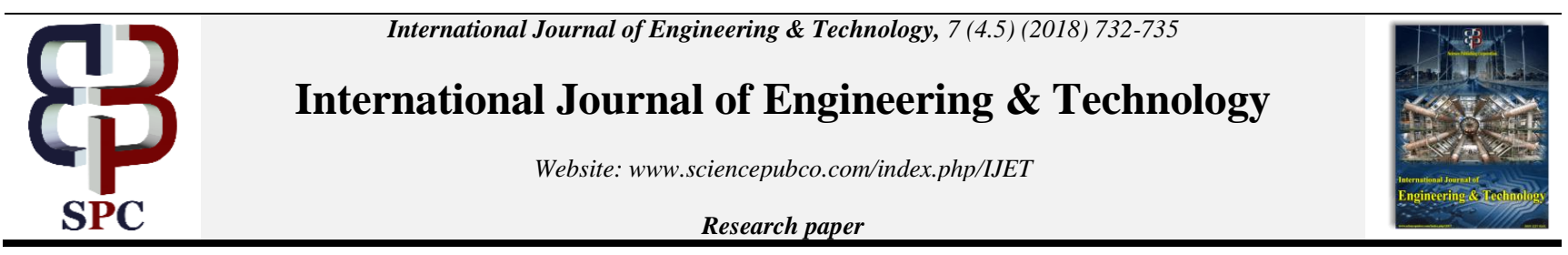

\title{
Symmetrical and asymmetrical cascaded multilevel inverter for photovoltaic system
}

\author{
J. Gowrishankar ${ }^{1 *}$, G. Balasundaram ${ }^{1}$, R. JayaKishore ${ }^{2}$, J. Belwin Edwardd ${ }^{3}$ \\ ${ }^{1}$ Associate Professor, Department of EEE, SVCET, Chittoor \\ ${ }^{2}$ M. Tech, P.G Student, Department of EEE, SVCET, Chittoor \\ ${ }^{3}$ Associate Professor, SELECT,VIT university \\ *Corresponding author E-mail: gowrishankar.vj@gmail.com
}

\begin{abstract}
In modern days, for enormous energy application, using multilevel inverter has mainly been used. because of the deduction of general harmonic distortion (THD) of the output voltage level and having low blocking off voltages of switches. within the existing system, dc voltage supply which is maintained perpetual is given as load to the inverters which contains the collection connection of mandatory block and is analyzed in balanced and unbalanced mode of operation to produces distinctive voltage levels. the proposed approach replaces the dc voltage provided to the photovoltaic (PV) cellular has been used which has variations interior of the output voltage features pivot on the solar irradiation steps. this photovoltaic cellular makes use of majority energy point tracking (MPPT) algorithm to produce required voltage as input to the multilevel inverter (mli) has to be maintained stable a fly back forward converter has been used in amid of the photovoltaic cellular and the multilevel inverter, so that the stated a doublet of unvarying output voltage has been obtained at the output of the converter. using the output of the converter 49 output voltage phase can be received from the multilevel inverter. from that, total potential loss across the switches and pinnacle inverse voltage (PIV) has been calculated. finally, a computer simulation the usage of MATLAB.
\end{abstract}

Keywords: Photovoltaic; Multilevel Inverter; DC-DC Converter

\section{Introduction}

In modern years, there may be fast growing of image voltaic (PV) producing device and their effect at the potential device operation has drawn additionally concerned. Photovoltaic (PV) structures canbe characterized through input voltages, current and the use of those inputs, several studies has been carried out to test the efficiency and characteristics in multi input PV structures having morevaluable max energy factor tracking(MPPT) [6]. The fixed DC output voltage from the MPPT set of orders is given as the input to the fore converter which splits the static DC voltage into different output voltage that's requiredfor asymmetric mode of operation to produce more stages in the inverter side. This fore converter specially specializes in RCD snubber circuit that is specifically used to lesser the ripples within the output side of converter [7]. in order that the input given to the multilevel inverter might be free fromripples. Several IGBT switches usage, indifferent DC supply, energy loss, overall harmonic distortion of output voltage waveform has been calculated pinpoint very exact when compared to other two strategies [8]. there aremany present topologies are being in developed for low switching frequency and excessive strength devices like static, electric powered cars etc., the principle importance of usage of multilevel inverters istherenewable resources like photovoltaic cell that is particularly used to strengthen figure 1: Simplified pictorial diagram of proposed forty-nine phase output voltage appliance. Multilevel inverters (MLI) have usually been used due to its immoderate voltageand immod- erate efficiency operation. It provides high energy and may perform the usage of multiple switches in place of one switch. MLI can use essential supply energies like wind and solar power and then get transformed into AC signal as a result the reliability of inverter get reduced which improves the efficiency of converter [8].

Cascaded $\mathrm{H}$ bridge inverters makes use of set of series pair of odd phase full bridge inverters to have multilevel phase with each having separate DC source. The efficiency of the contraption. on this paper, a new approach of multilevel inverter has been proposed that's generalized the usage of connection of blocks in sequence way of order that complete block is named as multilevel inverter, that is obviously designed to reduce the repletion of harmonic distortion(THD) and will have expanded the number of output voltage phase of the device, which in turn reduces the blockading voltages of the switches is used explicitly to get the sinusoidal waveform as output [10] as shown in determine 1. finally, a simulation of the proposed system using MATLAB was dispensed and a premier version has been applied to verifythe end result. 


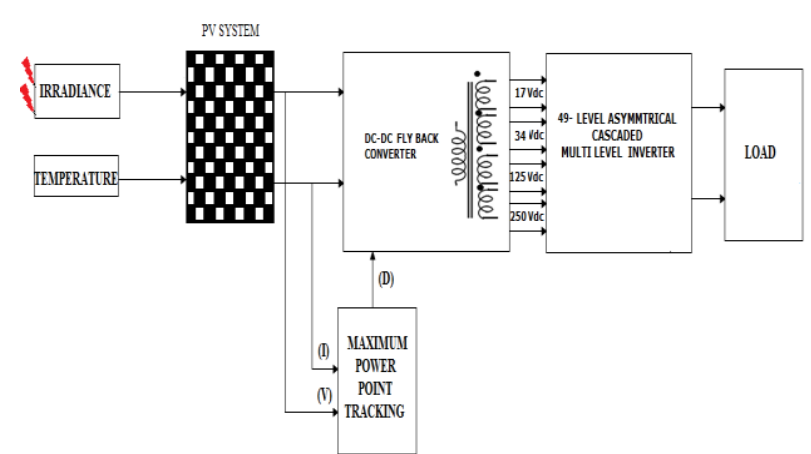

Fig. 1:Block Diagram of Asymmetrical Cascaded ML Fly Back Converters.

Two procedures're commonly utilized in modeling a Flyback converter the usage of the Averaged switch technique. the first manner is to reflect the burden to the primary side after which exchange of the FET and diode with perturbed and linearized models the use of a PWM transfer [15]. This approach seems to be very much less captivating because it takes very large effort to derive the Averaged version while thePWM switch models are always conveniently available for plug-in. the second one way of modeling is to derive the Averaged version at once without having the impedance reflections. however, this 2 nd model derived the usageof this approach is also seems additional complicated than the model derived the usage of a PWM switch, that is taken into consideration to be true for modeling Flyback. as a consequence, the PWM exchange modelingis subsequently observed to be most accurately alternative for modeling a Flybackconverter

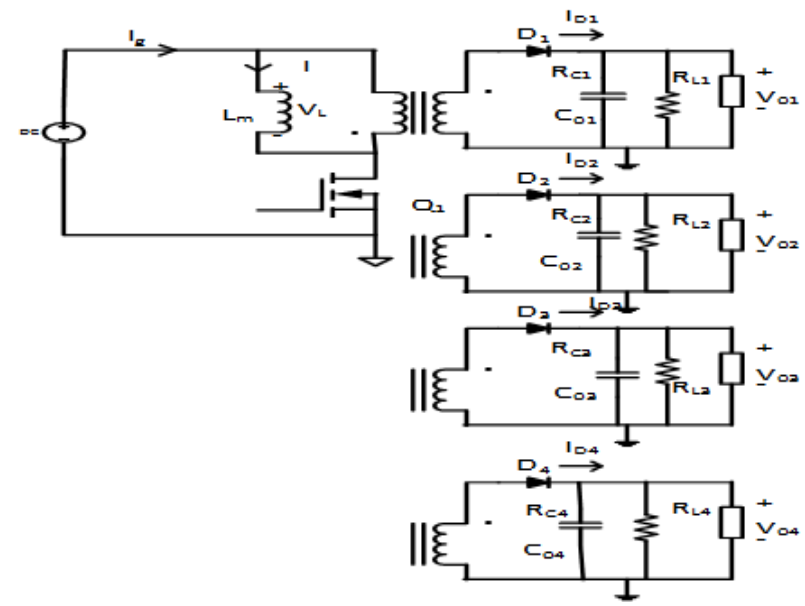

Fig. 2: Dc-Dc Flyback Converter with Different Output Voltage with R Load.

\section{Multilevel inverter}

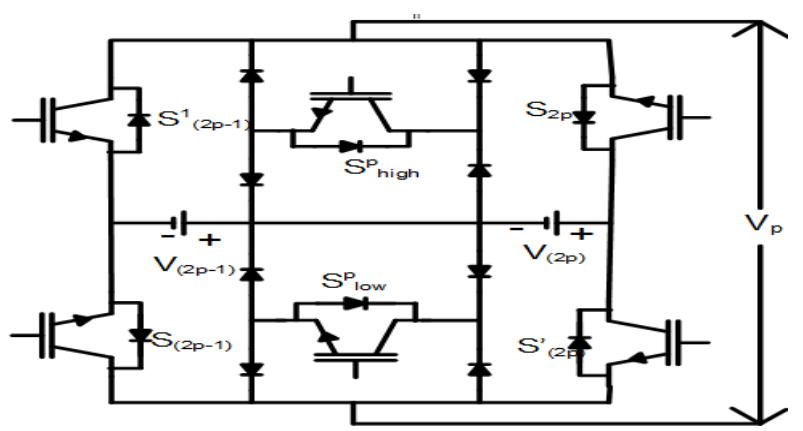

Fig. 3: Necessary Block of Multilevel Inverter.

.The above diagram determine 3 shows the necessary block of proposed multilevel inverter which consists of DC voltage resources. If the same voltage is carried out in two voltage supply then it's far stated to be in symmetric mode. however, if the volt- age source given is determined to be exclusive method it is running in asymmetric mode of operation. This block consists of six semiconductor switches which might be connected with the antiparallel diode. Itadditionallyincorporates eight diodes that are used for conduction of backward modern, which is resulting from inductive characteristics of load. The semiconductor switches used on this circuit is IGBT. The above circuit comprise various blocks that is important for the stages of operation. If the block is supposed to be first block ' $p$ ' value is replaced by way of 1 , so the switches range becomes S1, S1', S2, S2', Shigh1, Slow1, V1,V2. Symmetric mode

In this symmetric mode of operation, all DC resources are constant to be V. it may generate five stages in output voltage [8]. Turning the switches on and off in the right way, tow positive, two negative and two 0 voltage ranges have been acquired. As to the proper switching of gadgets, the redundancy in switching position can provide common power manipulate can be calculated the use of (12).

$\mathrm{V} 2 \mathrm{p}=\mathrm{V}(2 \mathrm{p}-1)=\mathrm{V}$

$\mathrm{V}(1)=\mathrm{V} ; \mathrm{V}(2)=\mathrm{V}$
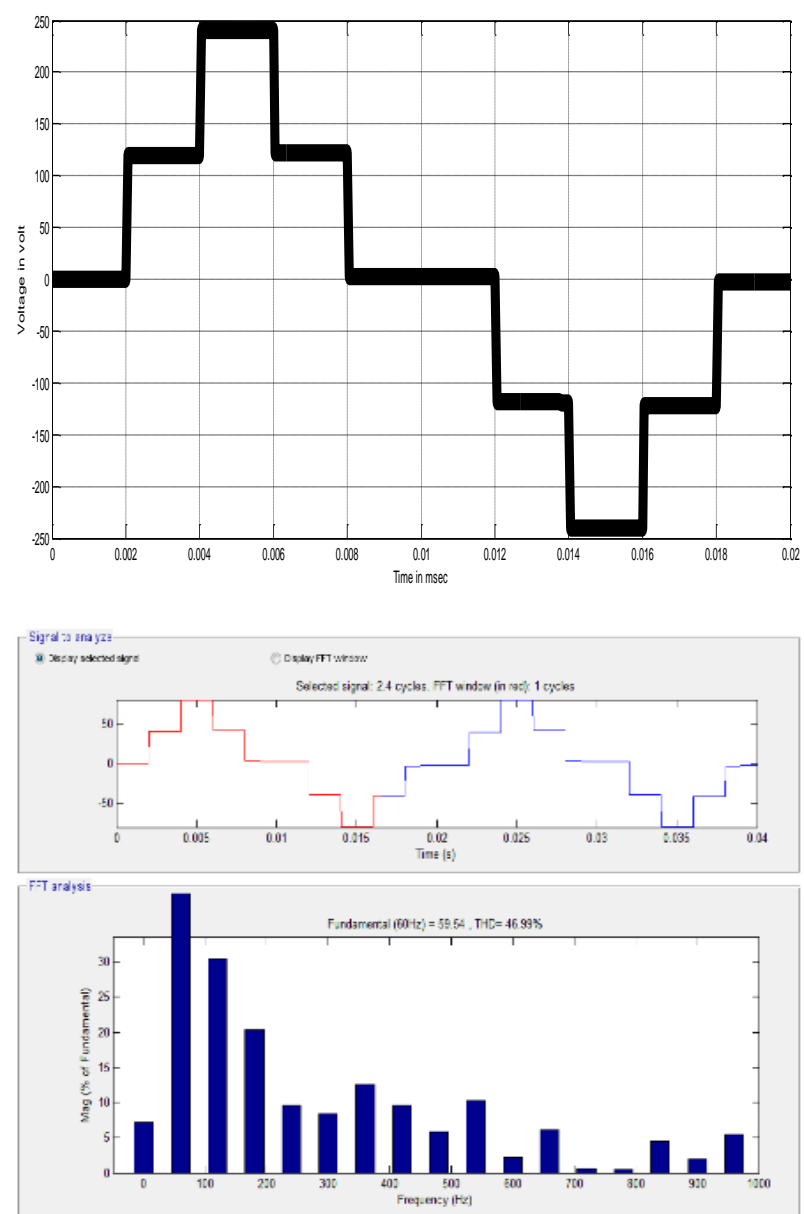

Fig. 4: 5-Level Output Voltage\& THD of Symmetrical Cascaded MLI.

\section{49-Level multilevel inverter}

The generalized multilevel inverter is fabricated with the aid of connecting the fundamental block in accumulate, in order that accumulated connection of blocks leads to the increase in degree of levels. on this proposed device, two primary blocks are associated in series and goes to perform in unequal mode of operation which has the functionality of producing forty nine levels the output voltage side. on this proposed method to attain the required output voltage level inside the circuit, distinctive DC voltage 
sources are given and the values are determined using theequation(14)

$\mathrm{r}=\mathrm{DC}$ voltage supply number

$$
\begin{aligned}
& \mathrm{V}(1)=\mathrm{V} ; \mathrm{V}(2)=2 \mathrm{~V} \\
& \mathrm{~V}(3)=7 \mathrm{~V} ; \mathrm{V}(4)=14 \mathrm{~V}
\end{aligned}
$$

The block diagram of the proposed system is shown in Figure 5:

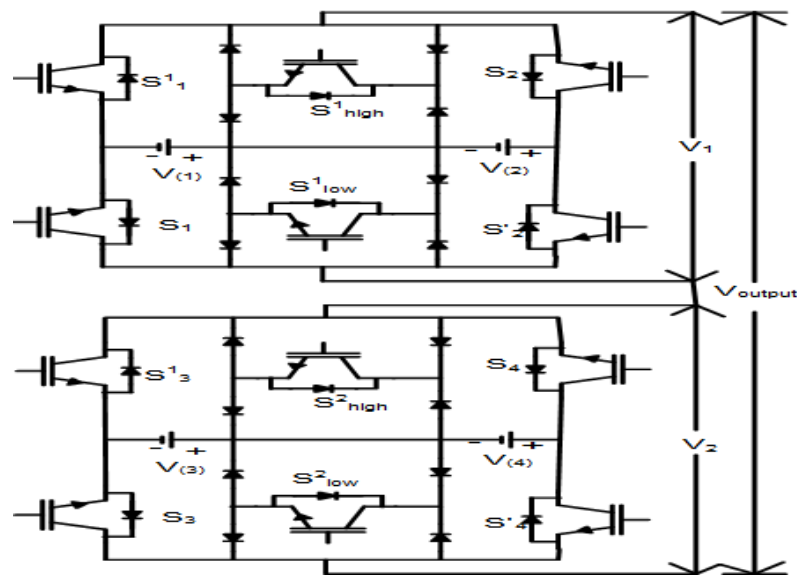

Fig. 5: 49-Level Cascaded Multilevel Inverter.
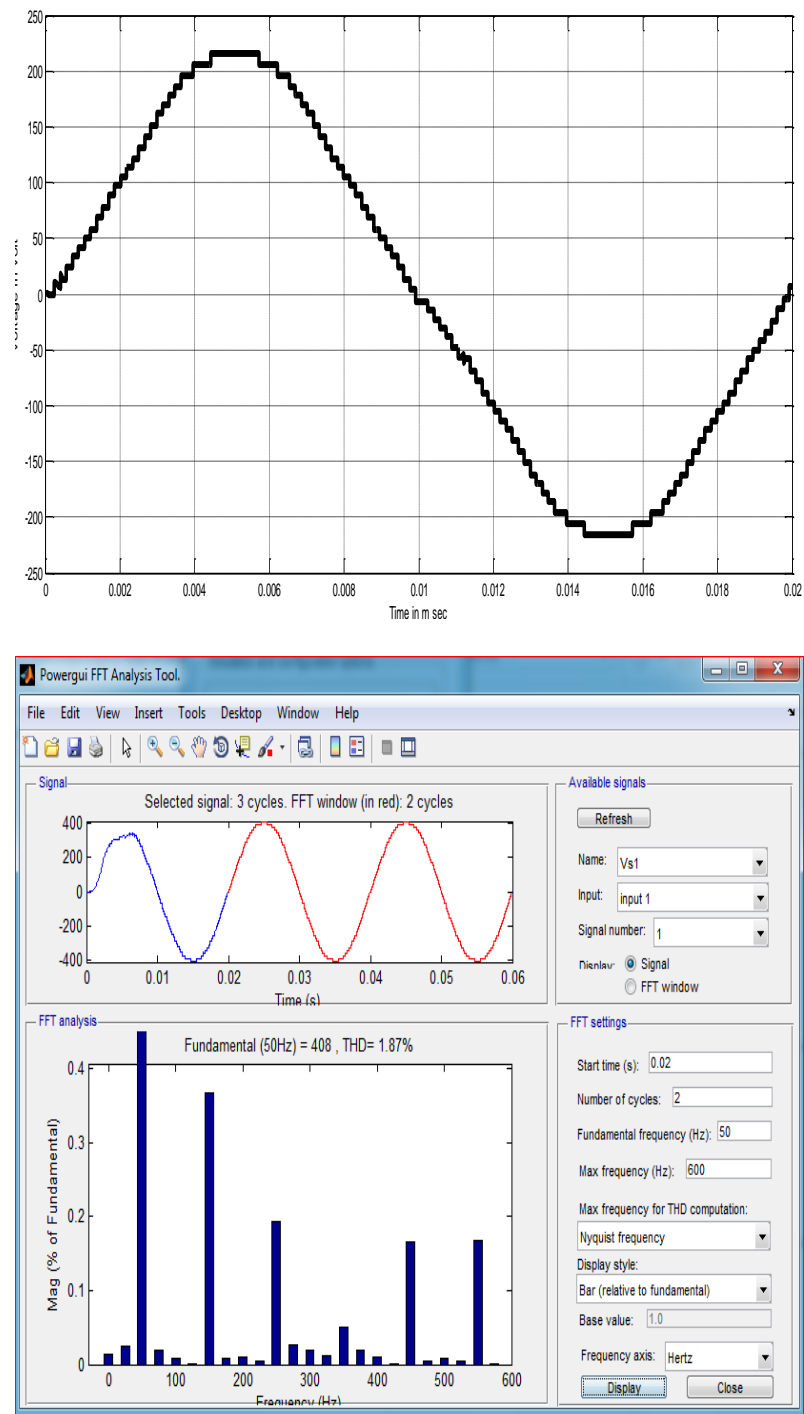

Fig. 6: 49-Level Output Voltage of \&THD Asymmetricalcmli.

\section{Simulation results}

DC link voltage is the voltage that is normally calculated in the connection where the rectifier and the inverter get connected. It is a topology of drive with DC link varies depending upon power rating of drive. As a result at lower voltage and power, the DC link stage typically has a capacitor in order to support the voltage between converter and inverter.
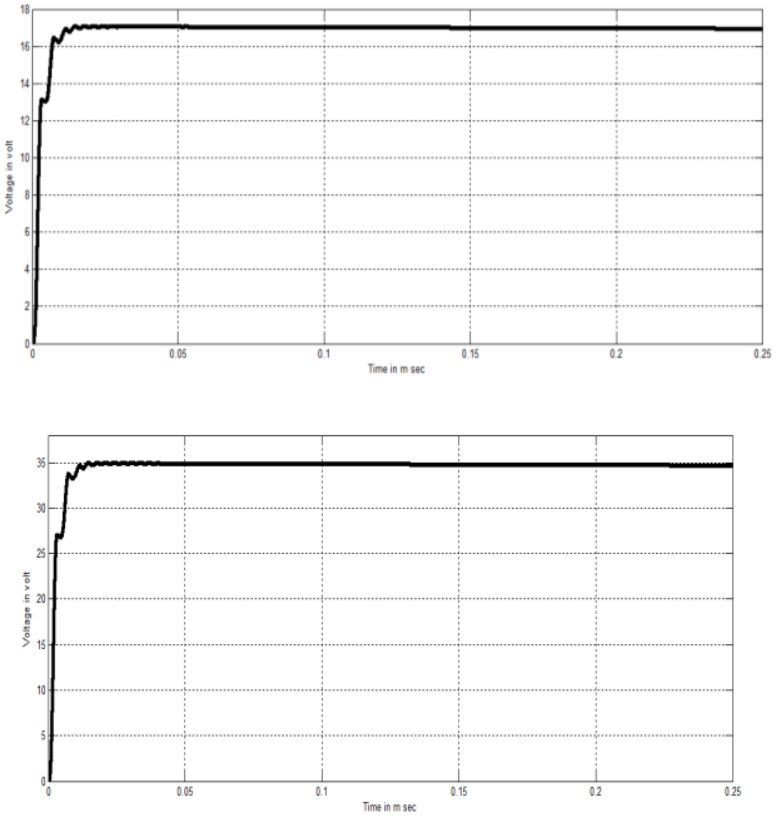

Fig. 7: DC Link Voltage on Converter Side $\mathrm{V}_{\mathrm{dc} 1} \& \mathrm{~V}_{\mathrm{dc} 2}$.
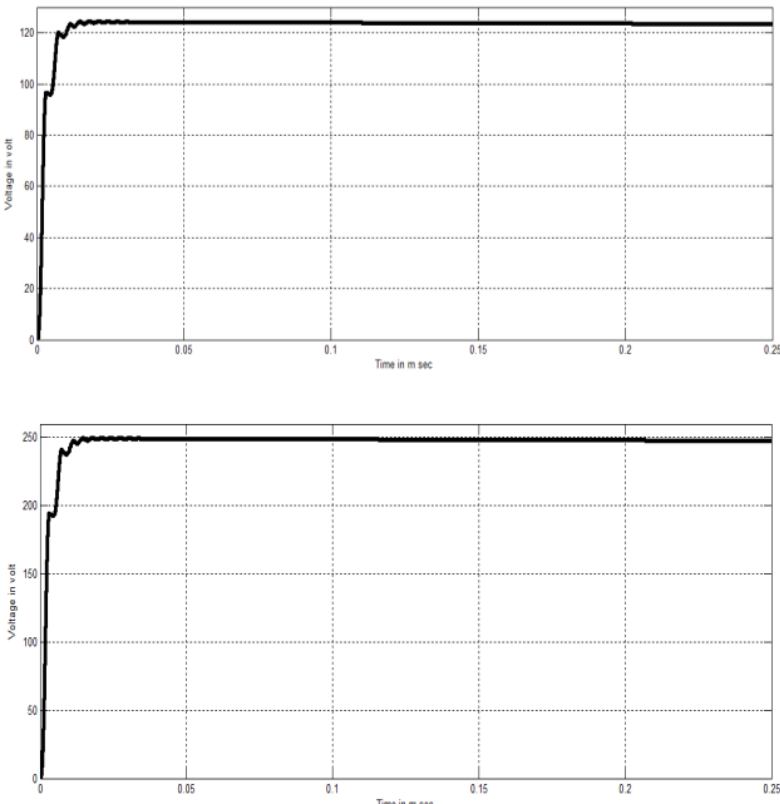

Fig. 8: DC Link Voltage on Converter Side $\mathrm{V}_{\mathrm{dc} 3} \& \mathrm{~V}_{\mathrm{dc} 4}$

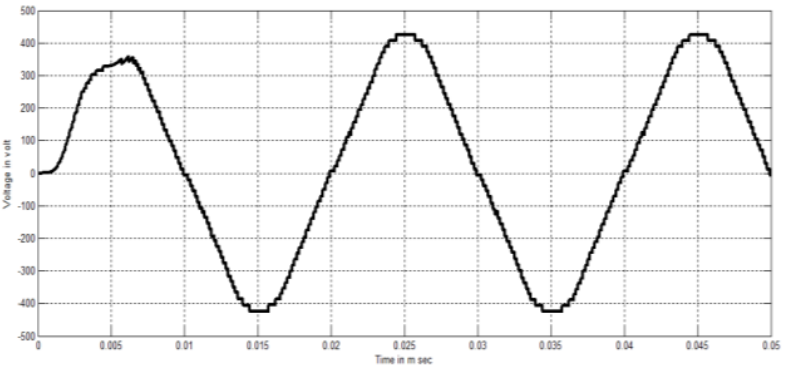

Fig. 9: Output Voltage of Proposed Circuit Showing 49 Levels 
Table 2: shows the Comparison of Symmetrical \& Asymmetrical CMLI

\begin{tabular}{lllllllll}
\hline & $\mathrm{V}_{1}$ & $\mathrm{~V}_{2}$ & $\mathrm{~V}_{3}$ & $\mathrm{~V}_{4}$ & $\mathrm{~L}$ & $\mathrm{THD}$ & $\mathrm{D}$ & $\mathrm{S}$ \\
\hline Schbmli & 120 & 120 & - & - & 5 & $46.9 \%$ & 8 & 6 \\
Aschbmli & 9 & 18 & 63 & 126 & 49 & $1.87 \%$ & 16 & 12 \\
\hline
\end{tabular}

\section{Conclusion}

Hence the 49 phase multilevel inverter has been proposed on this paper. The proposed topology has some special functions like use of photovoltaic cellular, reduced alternation of switches, and increase in output voltage levels of inverter. This paper additionally includes diverse analysis like locating the whole harmonic distortions (THD), blocking voltage and height inverse voltage(PIV) calculation using inverter circuit, as converter also blanketed in this proposed paper DC hyperlink voltage across the switchesss additionally has been calculated.As with the minimal number of switches greatervoltage stage hasbeen discover which enables in using this association in high voltage programs.inthe proposed device the operation of the switches has been segregated into high and lesser frequency part which likely to be reduce the volume and charge of the circuit. The input and output voltage and current waveforms that is required for the proposed machine has been observed out as four individual voltage of $15 \mathrm{~V}, 30 \mathrm{~V}, 105 \mathrm{~V}$ and $210 \mathrm{~V}$ has been taken and the output voltage obtained at the inverter is located to be $310 \mathrm{~V}$. The losses and PIV calculation being executed in the proposed circuit and the values are found to be comparatively lower when compared totheexisting device.

\section{References}

[1] Prabaharan N., Palanisamy K., and Rini Ann Jerin A.: Asymmetric Multilevel Inverter Structure with Hybrid PWM Strategy. International Journal of Applied Engineering Research, vol. 10, no. 55, pp. 2672-2676, (2015).

[2] Prabaharan N., Fathima A.H., and Palanisamy K.: New hybrid multilevel inverter with reduced switch count using carrier based pulse width modulation technique. 2015 IEEE Conference on Energy Conversion, CENCON 2015, pp: 176-180, (2015).

[3] J.Gowri Shankar, J. Belwin Edward "Implementation Of 5-Level Cascaded H-Bridge Multilevel Inverter With Single Dc Source For Photo Voltaic System Using Proteus " Journal of Electrical Engineering, Volume 16/2016, Edition 4.16, pp 127-132.J.

[4] J.Gowri Shankar, J. Belwin Edward " A 15 level Asymmetrical Cascaded H BRidge Multilevel inverter with less number of switches for photovoltaic system " 2016 International conferenceon Conference on Circuit, Power and Computing Technologies.

[5] BalasundaramG ,J.Gowri Shankar and C.Dinakaran "A New Topologies For Regulation Of Active Power By Battery Storage System With cascaded Multilevel inverter using three Phase system" Indian Journal of Science and Technology (IJST) Vol 9(22), June 2016,ISSN(Print) : 0974-6846,ISSN(online) : 0974-5645.

[6] Balasundaram.G, Arumugam.S "Single Phase Modified Seven Level Inverter With Less Number Of Power Switches For Solar Energy Applications" IJAER,Vol 10,No:9 (2015).

[7] Baskaran. J has published the paper entitled, "A New Dual Bridge Multilevel DC-Link Inverter Topology" on Elsevier PublicationInternational Journal of Electrical Power and Energy Systems 45 (2013) 376-383, September 2012.

[8] Baskaran. J has published the paper entitled "Carrierless pulse width modulation strategy for multilevel inverters" on IET, Power Electronics, Volume 8, Issue 10, June 2015, p. 2034 -2043.

[9] Gowri Shankar. J \&Belwin Edward. J "Implementation of 5-Level Cascaded H-Bridge Multilevel Inverter with Single DC Source for Photo Voltaic System Using Proteus" Journal of Electrical Engineering Vol 16.4. 2016) PP 127-132 ISSN: 1582-4594.

[10] Gowri Shankar. J \&Belwin Edward. J "Implementation of 9level Hybrid Inverter using Multi-Reference Pulse Width Modulation Technique with Fly Back Converter for Photo Voltaic System". International Journal of Control Theory and Applications, Vol. 10, No 37, 2017, pp 365-382. 